\title{
Literatura para criancas e jovens: panorama de linhas investigativas
}

José Nicolau Gregorin Filho

Universidade de São Paulo

\begin{abstract}
RESUMO: ESTE TRABALHO TEM COMO OBJETIVO A DISCUSSÃO DE ALGUMAS PERSPECTIVAS TEÓRICAS MAIS UTILIZADAS PARA A PESQUISA E O CONSEQÜENTE ENSINO DA LITERATURA PARA CRIANÇAS E JOVENS, JÁ QUE ESSE TIPO DE TEXTO VEM SE EXPANDINDO AO LONGO DOS ANOS E SE TORNOU DE GRANDE IMPORTÂNCIA PARA O MERCADO EDITORIAL, VISTO SEREM LIVROS MUITO CONSUMIDOS, OU POR FIGURAREM EM LISTAS DE LEITURA OBRIGATÓRIA NAS ESCOLAS, OU POR SEREM ADQUIRIDOS POR ENTIDADES GOVERNAMENTAIS LIGADAS À ÁREA DE EDUCAÇÃO.
\end{abstract}

ABSTRACT: THIS PAPER AIMS TO DISCUSS SOME MORE THEORETICAL PERSPECTIVES USED TO SEARCH THE LITERATURE AND THE CONSEQUENT LEARNING FOR CHILDREN AND YOUNG PEOPLE, SINCE THIS TYPE OF TEXT HAS BEEN EXPANDED OVER THE YEARS AND HAS BECOME OF GREAT IMPORTANCE TO THE PUBLISHING MARKET, BECAUSE THEY ARE TOO CONSUMED, OR INCLUDED ON LISTS OF REQUIRED READING IN SCHOOLS, OR ACQUIRED BY GOVERNMENTAL ENTITIES RELATING TO THE AREA OF EDUCATION.

PALAVRAS-CHAVE: LITERATURA INFANTIL - LITERATURA JUVENIL - CRÍTICA LITERÁRIA KEY-WORDS: LITERATURE FOR YOUNG PEOPLE - LITERARY CRITICISM 


\section{Introdução}

Quanto se pretende enfocar as possíveis perspectivas de pesquisa e ensino de literatura para crianças é importante salientar que elas não se constroem e não se fundamentam de maneira isolada e estanque, ou seja, que seguem uma orientação, o que torna evidente que se pode centrar o estudo numa perspectiva sociohistórica e vincular a pesquisa ou ensino a outros fatores, tais como uma proposta pedagógica ou um instrumental semiótico para a análise dos textos. O que se pretende discutir é exatamente o enfoque encontrado em linhas de pesquisa diversas e, em linhas gerais, como pretendem olhar para um tipo de texto que a sociedade passou a nomear como literatura infantil, principalmente após a segunda metade do século XIX.

Para que se chegasse nesses cinco quadros de orientação teórico-metodológica utilizados neste trabalho, analisaram-se os livros publicados na área, livros esses que se constituem peças fundamentais para a fundamentação de cursos sobre o tema, além de uma série de outros trabalhos de pós-graduação desenvolvidos em programas cujas universidades mantêm esse estudo em seus cursos.

Não se pensa em esgotar o assunto ou pormenorizar todos os aspectos que envolvem tais maneiras de olhar o objeto, não só pela brevidade do texto e de seu objetivo, mas por serem essas próprias orientações muito complexas e abrangentes.

Busca-se, dessa maneira, um breve panorama das linhas teóricas mais utilizadas na pesquisa e no ensino da literatura infantil, ou seja: a da crítica literária, a lingüística, a sociohistórica, a semiótica, a didático-pedagógica, a psicanalítica e a comparatista.

\section{Literatura para crianças e jovens: alguns olhares}

Segundo Barbosa (2006), "a crítica é o conhecimento conceitual, ou aspira a tal conhecimento". No final, almeja o conhecimento sistemático da literatura, a teoria literária.

É absolutamente importante perceber que a chamada literatura infantil/juvenil possui poucos trabalhos oriundos da mesma corrente da crítica literária que se ocupa de estudar as grandes obras da literatura universal e brasileira. 
A literatura voltada para crianças e jovens ainda é vista como uma literatura de menor valor por grande parte dos críticos literários, talvez pela sua origem e pela sua associação freqüente com os textos de prática pedagógica. Nomes notáveis dessa corrente que se ocupa da análise de obras do gênero são, muitas vezes, os mesmos que construíram carreiras voltadas para a área em grandes universidades, ou seja, num determinado momento de suas pesquisas voltaram seu olhar para esse tipo de texto.

De certo modo, a crítica literária às vezes se distancia da tarefa de estabelecer parâmetros de análise para obras da literatura infantil e juvenil, seja em razão de as últimas se construírem por meio de múltiplas linguagens, fato que a crítica tradicional não considera, seja pelas temáticas ou pela construção da linguagem verbal, fatos esses que também muito se afastam da literatura produzida para outros públicos.

Muitos são os trabalhos dedicados à literatura para crianças e jovens com o objetivo de explorar questões lingüísticas desse tipo de texto, tais como as marcas da linguagem oral nele presentes, diferentes tipos de registro do português em função da região de onde o texto tem origem ou a faixa etária de seu público-alvo etc.

O que se percebe nos estudos realizados nesta perspectiva é, na sua maioria, um quase que esvaziamento do aspecto literário ou artístico presente na obra, isto é, a obra passa a ser encarada de um ponto de vista pragmático, desvinculada de seu ideal artístico.

A chamada perspectiva sociohistórica tem como objetivo estudar a literatura infantil-juvenil numa situação diacrônica: buscando, por meio de evidências históricas, as relações produtoras de textos que se relacionam a um determinado momento da história e como tal tipo de texto tomou as características que hoje constituem a literatura para crianças e jovens.

Buscar toda genealogia da construção da narrativa ocidental a partir de textos orientais, por exemplo, até chegar ao gênero da fábula ou do conto; pesquisar as relações entre texto, história e movimentos sociais e verificar os suportes utilizados para a veiculação de diferentes gêneros textuais, bem como a relação entre texto e dinâmica de leitura, fazem parte desse tipo de perspectiva.

Assim, a convivência social e as formas de expressão das sociedades mais antigas são importantes estudos para que se expliquem as razões pelas quais 
os grupos foram criando métodos de passar as suas experiências de vida para as futuras gerações, além de se buscar, na mesma viagem da sociedade através do tempo, assim como o surgimento da infância como etapa diferenciada na vida do ser humano.

Tal perspectiva considera, atentamente, a temática de alguns textos produzidos para a sociedade como um todo e, em constantes processos de adaptação, receberam o rótulo de literatura para criança. Entre várias obras, pode-se citar As Viagens de Gulliver, livro que, em sua época, era uma crítica à civilização utilitarista e um meio deslumbrante para se observar a questão da alteridade. Com o passar do tempo e suprimidos alguns capítulos, a obra se torna uma aventura vivida por um gigante.

Outra boa contribuição que tal perspectiva oferece ao estudioso da área é a confecção de dicionários críticos, nos quais a produção para crianças figura associada à de outros autores e períodos, fornecendo um panorama temporal de produção desse tipo de livro.

Portanto, essa perspectiva tem como objetivo considerar a obra como produto da sociedade na sua busca por comunicação, estética e perpetuação de experiências que partem da individualidade do autor à socialização de sua busca num momento histórico definido e que pode ser levado para outros tempos e grupos sociais.

Importante ressaltar que esse enfoque de cunho sociohistórico tem estreitas ligações com a perspectiva comparatista que será mencionada no decorrer deste texto.

Fundamentada, ou nos estudos do Projeto Semiótico Greimasiano ou em ou na semiótica de Pierce, esse tipo de enfoque tem como principal questão a análise da obra como um conjunto de signos que se constituem num discurso, uma perspectiva que busca, nas diferentes linguagens que constroem o texto (já que a literatura para crianças e jovens tem na contemporaneidade um hibridismo no que se refere às linguagens utilizadas em sua composição), seu instrumental primeiro de análise.

Os estudos baseados em Greimas procuram fazer uma análise imanente do texto, partindo de elementos mais concretos e perceptíveis na manifestação textual (personagens, espaço, ações concretas etc.) para, em momentos posteriores, buscar nas camadas mais profundas da estrutura textual o nível mais abstrato, em que se podem verificar as relações de valores de que o texto trata. 
Pela própria historicidade do gênero, não se deve descartar a literatura para crianças e jovens como um objeto de estudo ou de ensino nos cursos de formação de professores ou como área de programa de pós-graduação. Pois a literatura para a criança deve ser oferecida como arte e prazer, arte porque é o resultado de um fazer estético do(s) autor(es) e prazer porque o contato com a arte pode ser encarado desde a mais tenra idade como uma experiência ricamente prazerosa, capaz de nos envolver e trazer novas dimensões ao cotidiano.

Assim, a perspectiva pedagógica para a pesquisa-ensino de literatura infantil tem como objetivo voltar a atenção de futuros profissionais da educação para sua diversidade, no sentido de que um livro pode ser aplicado em atividades lúdicas, artísticas e como importante aliado das práticas docentes que envolvem o ler, o escrever e, principalmente, o desenvolvimento de posturas investigativas e críticas do aluno.

Aliada a esta perspectiva de cunho pedagógico, outras são importantes. Por meio da preparação de novos profissionais para o trabalho com o livro, podemos levar o ambiente escolar a compreender e questionar aspectos históricos e sociais de um povo, educar o olhar para o universo de imagens e signos do mundo contemporâneo e, ainda, perceber comportamentos e atitudes de alunos ou grupos de alunos.

Outro fator de relevância para que se atente para essa perspectiva é a criação dos Parâmetros Curriculares Nacionais, derivados da Lei de Diretrizes e Bases da Educação Nacional (Lei 9394/1996) que deram origem aos temas transversais. Nesse ponto, a literatura pode e deve ser vista como ferramenta importante para o início das discussões geradas pelos temas, tais como a pluralidade cultural e ética, entre outros.

Não se deve colocar de lado, nesse enfoque, a questão dos suportes textuais, pois cada época, em razão de suas conquistas tecnológicas e de seus saberes, presenciou a veiculação dos textos de maneira diferente e mais adequada às suas relações sociais.

Estudar a leitura da literatura, seja ela para crianças ou não, é, em última análise, estudar como o homem se relaciona com os demais e com o seu meio. Isso faz com que o profissional encontre meios adequados até para a difusão dos próprios textos em sala de aula. Assim, buscam-se novos métodos e suportes textuais para satisfazer às necessidades dos curiosos internautas de hoje. 
Assim, não é porque a literatura para crianças e jovens pode ser investigada nesta perspectiva que ela se torna menor ou deixa de ser arte, pelo contrário, abrem-se, por meio dela, novas possibilidades interpretativas para que os docentes possam olhar com mais cuidado e com mais segurança para os livros e as atividades por meio deles criadas e aplicadas.

Essa orientação teórico-metodológica tem algumas relações com a perspectiva psicanalítica, pela razão de buscar nos estudos da psicologia elementos que possam trazer orientações sobre as fases de amadurecimento da criança. Percebase que, nesta perspectiva que se nomeia didático-pedagógica, encontra-se muito mais vínculo com a psicologia do que com a psicanálise propriamente dita.

Fundamentada principalmente nos estudos da psicanálise de Freud e Jung, a perspectiva psicanalítica encontra na literatura para crianças e jovens um importante recurso para os estudos da psique e do comportamento humanos.

Os principais trabalhos desenvolvidos sob a perspectiva psicanalítica têm, entre outros gêneros literários, os contos de fada como seu principal objeto de estudo, visto serem eles valiosos elementos para que se estudem, por exemplo, os arquétipos e símbolos das relações humanas, sociais, familiares e de gênero.

Nos contos de fada, podem ser vislumbrados indicativos de comportamentos que sinalizam importantes questões ligadas à sexualidade, aos complexos de Édipo e de Narciso, entre outros. Por exemplo, em Branca de Neve e Cinderela, a perda da figura da mãe e a conseqüente inserção da figura da madrasta são de grande valor para que se questione o papel da mulher, sua relação com pai e mãe, e a resolução de questões edipianas.

Abordagens de Melanie Klein podem referenciar outros contos, os quais fornecem subsídios para que se possam analisar fatores relacionados à solução de problemas ligados ao crescimento e ao amadurecimento, tais como a saída do lar e a escolha por seus próprios caminhos, como se verifica em Chapeuzinho vermelho e João e Maria.

A maior parte dos trabalhos desenvolvidos nesta perspectiva tomam os contos de fadas como objeto de análise, mas outras obras também se mostram muito valiosas para essa visão, já que a sociedade procura discutir questões como a alteridade, a sexualidade e a violência no âmbito escolar e, desse modo, pais, educadores e outros profissionais envolvidos no processo de educação encontram, nos estudos que se fundamentam na psicanálise, importantes aliados para a resolução de questões inerentes ao comportamento humano. 
Do que já foi exposto, pode-se ter a idéia de que nenhuma das perspectivas citadas anteriormente se sustenta isoladamente; também é preciso ter em mente que o trabalho de pesquisa e a prática de ensino da literatura não devem ser restritos ao âmbito da teoria da literatura tradicional.

Nessa linha, a perspectiva comparatista, que começa a ser utilizada em pesquisas sobre a literatura para crianças e jovens e tem sua origem na Literatura Comparada, vem se tornando cada vez mais apropriada para levar o indivíduo a relacionar uma determinada obra literária com o seu contexto de produção e com outros textos, num diálogo mais abrangente em busca das relações de alteridade no âmbito das trocas culturais.

Desse modo, esta orientação procura inserir uma obra num âmbito textual mais amplo, já que nenhum texto nasce isolado na sociedade. Buscar contextos de produção e recepção, relacionar a obra com a sociedade que a produziu, procurar nessa mesma sociedade as questões que fizeram emergir um dado texto são questões envolventes e cujo trabalho pode se transformar em grande elo interdisciplinar, já que este tipo de análise se constituirá numa linha fronteiriça e necessitará de auxílio de outras áreas do conhecimento.

Um texto de jornal, uma peça publicitária ou uma novela de televisão podem ter relações de fundo com obras de cunho literário. Uma pintura ou uma escultura podem ser diferentes formas de materialização de um discurso que marca um conflito de valores sociais numa determinada época.

Além disso, buscam-se as relações de interface entre os textos e os movimentos socioeconômicos e culturais desencadeadores de uma série de transmigrações artísticas; tais como as temáticas, os gêneros e as possíveis influências exercidas no âmbito cultural e artístico por meio de processos colonizadores, por exemplo.

Mais do que entender as escolas literárias e seus principais representantes, diferenças específicas entre um gênero e outro, forma-se um leitor a partir das relações que ele consegue estabelecer por meio do diálogo de uma obra com outras, do mesmo tempo ou de tempos diferentes; da obra literária com outros gêneros discursivos; da época de enunciação da obra em questão com outros tempos, com outros homens, com outras sociedades.

Nessa perspectiva, o diálogo se inicia na obra e a ela retorna, após uma longa cadeia de associações com outros saberes e, nessa viagem, a pluralidade do leitor vai sendo construída; seja porque busca outros textos para esses diá- 
logos, seja porque aprende a importância do próprio diálogo. Tem-se, nesse entendimento, uma exploração de todos os elementos desencadeadores da gênese da obra literária. Por ser um estudo de fronteira com outras disciplinas e ciências, o cuidado que o estudioso deve ter é centrar-se no seu objeto literário para que a pesquisa não se torne uma pesquisa sociológica, política ou antropológica, por exemplo.

\section{Considerações finais}

O propósito deste trabalho era apresentar, ainda que de maneira panorâmica, as perspectivas de pesquisa e de ensino da literatura para crianças e jovens mais utilizadas no Brasil.

Não se pretendeu atribuir juízos de valor sobre o maior ou menor alcance ou validade desses quadros teórico-metodológicos, prestigiando essa ou aquela maneira de encarar o objeto de estudo. A partir desta discussão, o que se pode fazer é afirmar que, em todas elas, há uma necessidade específica que se pretende satisfazer com o estudo pretendido e, principalmente, que todas elas se complementam e representam importantes avanços de olhar para esse tipo de literatura produzida para um público tão particular.

A partir do foi exposto, nota-se a importância que cada um desses olhares tem sua contribuição para o entendimento do gênero, pois se sabe que a própria concepção de infância surgiu de alterações profundas das relações sociais e, desse modo, tanto a infância como a literatura para ela produzida ainda contempla uma gama inesgotável de variações.

Nem a conceituação de infância, nem os livros elaborados para o público infantil, e nem mesmo a sociedade são estanques e alheios a mudanças; pelo contrário, modificam-se e conclamam grandes mudanças das ciências que as toma como objeto de estudo.

Dessa forma, percebendo o caráter híbrido e fronteiriço do objeto de estudo, uma das perspectivas se sobrepõe, num primeiro momento, às outras em termos da metodologia e da abrangência de sua atuação: a perspectiva comparatista. Utilizando-se dessa perspectiva, o estudioso consegue se aproximar de diferentes questões acerca do problema central, ao mesmo tempo em que se cerca de diferentes campos de estudo para um entendimento mais global do seu objeto. 
Evidente que, depois da análise desse universo maior de compreensão que essa orientação proporciona e em face de objetivos específicos para cada trabalho de pesquisa, buscar-se-ão novas orientações teórico-metodológicas para que se alcancem de maneira mais clara e fidedigna os propósitos que cada pesquisador, almeja em sua área e um olhar mais apurado para as diferentes nuances que a literatura para crianças e jovens pode solicitar.

\section{Referências Bibliográficas}

ARROYO, Leonardo. Literatura Infantil Brasileira. São Paulo: Melhoramentos, 1988.

BARBOSA, João Alexandre. Criação e crítica literária. Revista Via Atlântica, n. 9, p. 113-118, 2006.

BETTELHEIM, Bruno. Psicanálise dos contos de fada. Rio de Janeiro: Paz e Terra, 1978.

CAMARGO, Luís. A ilustração do livro infantil. Belo Horizonte: Lê, 1995.

CARVALHO, Bárbara Vasconcelos de. A literatura infantil. São Paulo: Global, 1984.

CEREJA, William Roberto. Ensino de Literatura: uma proposta dialógica para o trabalho com literatura. São Paulo: Atual, 2005.

CHARTIER, Roger. A aventura do livro: do leitor ao navegador. São Paulo: Ed. Unesp; Imprensa Oficial do Estado de São Paulo, 1999.

COELHO, Nelly Novaes. Panorama histórico da literatura infantil e juvenil. São Paulo: Ática, 1991.

- Dicionário crítico da literatura infantil brasileira. São Paulo: Edusp, 1995. - A literatura infantil. São Paulo: Moderna, 2000.

. O conto de fadas: símbolos, mitos, arquétipos. São Paulo: DCL, 2003.

COUTINHO, Eduardo; CARVALHAL, Tânia F. Literatura Comparada: textos fundadores. Rio de Janeiro: Rocco, 1994.

DINORAH, Maria. O livro na sala de aula. Porto Alegre: LP\&M, 1987.

EVANGELISTA, Aracy Alves. M. (Org.). A escolariz̧ação da leitura literária: o jogo do livro infantil e juvenil. Belo Horizonte: Autêntica, 2003.

GÓES, Lúcia Pimentel. A aventura da literatura para crianças. São Paulo: Melhoramentos, 1991.

Olhar de descoberta. São Paulo: Paulinas, 2004.

. Em busca da matriz: uma contribuição para a História da Literatura Infantil

Portuguesa. São Paulo: Cliper; Fac. Teresa Martin, 1998.

GREGORIN FILHO, José Nicolau. A roupa infantil da literatura. Araraquara/SP, 1995.

Dissertação apresentada à FCL-UNESP. 
. Figurativização e imaginário cultural. Araraquara/SP, 2002. Tese apresentada à FCL-UNESP.

. Literatura infantil brasileira: da colonização à busca da identidade. Via Atlântica, n. 9, p. 185-194.

HELD, Jacqueline. O imaginário no poder. Trad. Carlos Rizzi. São Paulo: Summus, 1980.

JESUALDO, J. A literatura infantil. São Paulo: Cultrix; USP, 1978.

KHEDE, Sônia Salomão (Org.). Literatura infanto-juvenil: um gênero polêmico. Petrópolis/RJ: Vozes, 1983.

. Personagens da literatura infanto-juvenil. São Paulo: Ática, 1986.

LAJOLO, Marisa; ZILBERMAN, Regina. Literatura infantil brasileira. São Paulo: Ática, 1984.

LAJOLO Marisa. Usos e abusos da Literatura na escola. Rio de Janeiro: Globo, 1982.

MORAES, Antonieta Dias de. Reflexos da violência na literatura infanto-juvenil. São Paulo: Letras e Letras, 1991.

PALO, Maria José; OLIVEIRA, M. Rosa. Literatura infantil. São Paulo: Ática, 1986.

PERROT'TI, Edmir. O texto sedutor na literatura infantil. São Paulo: Ícone, 1986. . Confinamento cultural, infância e leitura. São Paulo: Summus, 1990.

RESENDE, Vânia. Relatos de uma experiência na escola. Belo Horizonte: Comunicação, 1983.

Literatura infantil \& juvenil: vivências de leitura e expressão criadora. São Paulo: Saraiva, 1993.

ROSEMBERG. Fúlvia. Literatura infantil e ideologia. São Paulo: Global, 1984.

SOUZA, Ângela Leite de. Contos de fada: Grimm e a literatura oral no Brasil. Belo Horizonte : Lê, 1999.

VALE, Fernando Marques do. A obra infantil de Monteiro Lobato: inovações e repercussões. Lisboa: Portugalmundo, 1994.

VON FRANZ, Marie-Louise. A sombra e o mal nos contos de fada. São Paulo: Paulinas, 1985.

A interpretação dos contos de fada. São Paulo: Paulus, 1990.

YUNES, Eliana; PONDÉ, M. da Glória. Leitura e leituras da literatura infantil. São Paulo: FTD, 1988.

ZILBERMAN, Regina (Org.). Leitura em crise na escola. Porto Alegre: Mercado Aberto, 1982.

. (Org.). A produção cultural para crianças. Porto Alegre: Mercado Aberto, 1982. - A literatura infantil na escola. São Paulo: Global, 2003.

WORNICOV, Ruth et al. Criança, leitura, livro. São Paulo: Nobel, 1986. 